\title{
Right Evaluation of Products and Compliance Measures
}

\author{
Linda J. Kelly
}

\begin{abstract}
The global medical device market is worth billions. In fact, a new report by the independent media company Visiongain predicts that the global medical devices market will reach $\$ 398$ billion in 2017. In the field of infusion and vascular access, there is an enormous range of products, supplies, equipment and instruments available. The right evaluation of a product is necessary to test the clinical application, expected outcomes, performance, infection prevention, safety, efficacy, reliability and cost of these new products. Facts gained from product evaluations provide vital information that will either support the introduction of the product or provide reasons to reject it. Effective, well-informed product evaluation and purchasing can prove to ensure best patient outcomes, reduce rising costs or, in the best-case scenario, offer a balance of these two outcomes.
\end{abstract}

\section{Keywords}

Product evaluation - Purchasing decisions . Product evaluation form $\cdot$ Product evaluation process $\cdot$ Goals for product evaluation

L. J. Kelly $(\square)$

Edinburgh Napier University, School of Health and Social Care, Edinburgh, UK

\subsection{Introduction}

Product evaluation is a fundamental component in the promotion of patient safety requiring a structured, multidisciplinary approach to ensure effectiveness. It is important that clinical end users are involved in the evaluation of infusion and vascular access-related technologies as they are the best qualified to evaluate the performance, safety, effectiveness and efficiency of products used in their clinical area or healthcare setting (Philips 2017). A clinical evaluation should not be a discrete event, but rather, part of an ongoing process conducted throughout the life of a medical device, from initial product design and development, to regulatory review and approval, and finally, throughout product use once placed on the market.

This chapter provides general information about the evaluation of products, equipment and devices. It provides guidance for the evaluation process, discusses who should be involved in the evaluation, what to do with findings from the evaluation and the role of manufacturers in the evaluation process.

\subsection{Product Evaluation}

The reasons for introducing new products into the workplace are multiple and include replacing products no longer available, standardization 
across organizations, meeting the request or need of clinicians, cost-saving initiatives and attempts to improve patient and staff safety through improving patient outcomes. Emerging technologies have also led to the development of new products that require evaluation prior to adoption. In recent decades, there have been major advances in medical technologies. These advances have had a positive impact on patient outcomes by improving diagnoses and enabling more effective treatments (Burns et al. 2007). These advances do not come without a cost, and therefore we must be certain that decisions regarding the introduction of innovative technologies, devices, equipment and supplies are well evaluated.

In current times, a plethora of infusion and vascular access products are available, and there is a need to ensure that evidence is available to support the introduction or change of product. This is important due to the competition for limited finances, which is often fierce. Within the field of vascular access, we have seen such growth of new and innovative products. Many of these new products promise to improve patient outcomes by reducing infections or occlusions. There are also products, devices and equipment that claim to increase safety for both staff and patients and finally those that will improve the success of device insertion. As with any product, efforts should be made to validate claims within the specific facility and practice through product evaluation and trialling prior to final adoption. Even after adoption, a plan to follow-up by checking compliance and performance is needed to prove continued value and need for a product. The following section will provide an overview of some of these innovative products.

\subsection{Emerging Technologies in Intravenous Therapy and Vascular Access}

As we are aware, vascular access devices are utilized for most types of intravenous therapy and provide reliable access in most healthcare settings. With the development of healthcare technology, easier and safer insertion techniques and a greater selection of devices to choose from, the number of vascular access devices on the market continues to grow. Apart from the obvious groups of devices (peripheral venous cannula, extended dwell cannula, midline and peripherally inserted central catheter, tunnelled central venous catheter and totally implanted port), each of these devices can be further categorized as they are designed in numerous ways and with varying designs:

- Materials such as polyurethane or silicone.

- Can have valves incorporated or remain open ended (tapered or non-tapered).

- Can be impregnated with silver, antibiotics, etc.

- Introduction of safety devices.

Because of the range of devices available, there is often a selection of similar devices with differing design and materials available in a single organization. To improve patient safety and to reduce any potential risk, the decision is often made to standardize products.

\subsubsection{Dressings}

Once a vascular access device is inserted, the aim is for it to remain in situ for the treatment period. The consequences of a failed or dislodged catheter include interruption of medical treatment and the need for a replacement vascular access device which comes with potential insertion complications and possible negative patient experience (RobinsonReilly et al. 2016). The purpose of a dressing is to:

- Protect the site from microbial contamination from the surrounding skin and environment.

- Prevent dislodgement.

- Prevent micromotion within the vein which increases the risk of phlebitis (Ullman et al. 2016).

The range and design of dressings has and continues to increase and now includes:

- Chlorhexidine-impregnated dressing.

- Sutureless securement devices (SSDs). 
- Integrated securement devices (ISDs).

- Tissue adhesives, a medical grade super glue.

\subsubsection{Needle-Free Connectors}

Since their introduction, the range of needle-free connectors (NFCs) has exploded, and there is now a vast array of NFCs with various characteristics available. These numerous branded products also vary in their design and function (Kelly et al. 2017). The differences include:

- Visual appearance: Colour, shape, etc.

- Differences in internal mechanisms which are responsible for how the device functions.

- Presence of an integrated and extension line (single or multiple).

- Incorporation of valves and filters.

- Inclusion of occlusion management systems.

\subsubsection{Port Cleaning Caps}

Port cleaning or disinfecting caps are devices that offer an engineered solution to hub disinfection. Their use is aimed at reducing compliance of needle-free connector disinfection (Moureau and Flynn 2015; Cameron-Watson 2016). These caps are impregnated with a disinfection solution. The cap is placed on the hub of a needless connector and remains in place until the device is next accessed, allowing for standardization and compliance. Following use, the cap is discarded and a new one is then attached. The caps are available with various antimicrobial solutions including $70 \%$ alcohol, iodinated alcohol, povidone-iodine gauze and chlorhexidine/alcohol (Moureau and Flynn 2015).

\subsubsection{Vein Visualization Technology}

Ultrasound technology has been found to be invaluable in vascular access procedures, particularly for deep veins (Lamperti et al. 2012; Simon and Saad 2012). However, there is now a range of near-infrared devices available that are useful for peripheral cannulation of the more superficial veins (Kelly 2013; Lamperti and Pittiruti 2013). This technology is still relatively new, and although there have been some evaluations, to properly understand the potential benefits of this technology, further evaluations are necessary (Phipps et al. 2012).

\subsubsection{Tip Location Devices}

Historically, the tip of a PICC position was estimated by external landmarking and confirmed using a chest X-ray. The success rate of this technique remains variable between practitioners (Roldan and Paniagua 2015). Chest X-ray tip confirmation has also raised controversy in the literature (Plkwer 2008). Technologies to assist in tip guidance and location continue to evolve, and there are a wide range of such technologies now available. They rely on electrocardiology tracings, but once again, these products vary in design and function, and differences in products include:

- Inclusion of magnetics-external systems for locating tip position.

- ECG only technology without magnets.

- Doppler technology.

\subsection{How Do We Decide Which Is the Right Product?}

The selection and adoption of the right products involves a lot of effort, and decisions made must be fully justified. When faced with such a widerange and diverse number of products, decisionmaking must be evidence-based, and product evaluation helps to provide practical evidence of the product in clinical situations. To be effective, product evaluations must be systematic and well planned. One way to ensure this is to set early goals and aims of what is expected from the evaluation. Examples of product goals include:

- To reduce the rate of occlusions.

- To reduce the rate of infections.

- To increase compliance.

- To save nursing hours. 
Setting goals allows you to pinpoint and focus on the expected outcomes of the product introduction or change. Once the decision is made to introduce a new product, a structured approach should be taken to ensure that the process runs smoothly. This first step is to produce a written proposal of intent and to begin to explore the options that are available on the market.

\subsection{Discovering New Products}

Part of the role of practitioners in infusion and vascular access specialties is to be aware of the market and any new or innovative technologies emerging. There are a few ways in which we become aware of emerging technologies, and to do so effectively requires a thorough exploration of the market. Information can be obtained from an independent review of literature. Journal articles focusing on product evaluations and research papers provide invaluable information giving details of the outcomes of product use in practice (Jeanes and Bitmead 2015; Ventura et al. 2016; Barton et al. 2017). Conferences, study days and trade shows are also a fantastic arena for companies to display and demonstrate products. Detailed product brochures are often available and can be taken away for future perusal. A trade show or conference that is clinically focused and aimed at specific specialties such as intravenous access provides an ideal environment for the exploration of available products. In these settings, the ability to question the manufacturers and get hands-on demonstrations helps to narrow the field in the preliminary stages of product evaluation. Visits to other hospital sites currently using the product provides another way to gain information and to visualize the product in use. This sharing of experience and outcomes generally proves to be one of the most valuable evaluation stages.

\subsection{The Right Evaluation Form}

The use of an evaluation tool is vital to help standardize the evaluation. This tool should glean the following information:
- Does the product meet the objective?

- Does the product meet the need of the patient?

- Does the product solve a problem?

- Does the product prove cost-effective?

- Does the product improve patient care?

- Does the product compare with others?

The use of an evaluation tool encourages objective ratings in addition to make comparisons of comparable products. Again, the information gained from this stage of evaluation will narrow the field of suitable products and guide you toward the products that will eventually be included in the 'hands-on' evaluation. The general information detailed on the evaluation form includes:

- Name of product.

- Manufacturer.

- Name of evaluator.

- Date of evaluation.

The evaluation tool should subsequently focus on the product and gain more specific information. An example of an evaluation tool for a midline device is shown below.

\subsection{Midline Catheter Evaluation}

Product name:

Manufacturer:

Name of person completing

evaluation:

Designation:

Date of evaluation:

\begin{tabular}{l|l|l}
\hline Features & Consideration & Comments \\
\hline Packaging & $\begin{array}{l}\text { Size: will the storage and } \\
\text { discarding of the } \\
\text { packaging be an issue? }\end{array}$ & \\
& $\begin{array}{l}\text { Is the product package } \\
\text { easy to open? } \\
\text { Can sterility be maintained } \\
\text { easily during opening? }\end{array}$ & \\
\hline Length & $\begin{array}{l}\text { Are all necessary device } \\
\text { lengths available? }\end{array}$ & \\
\hline Lumen & $\begin{array}{l}\text { Are all necessary Fr sizes } \\
\text { available? } \\
\text { Is it available in } \\
\text { millilumen options? }\end{array}$ & \\
\hline
\end{tabular}




\begin{tabular}{l|l|l}
\hline Material & $\begin{array}{l}\text { Is the device radiopaque? } \\
\text { Is the device power } \\
\text { injectable? } \\
\text { Is the device flexible on } \\
\text { insertion? } \\
\text { Does the device maintain } \\
\text { its shape? }\end{array}$ & \\
\hline Ease of & $\begin{array}{l}\text { Is the needle sharp? Does } \\
\text { it have sharp safe features? }\end{array}$ & \\
insertion & $\begin{array}{l}\text { Is the wire of an adequate } \\
\text { length? } \\
\text { Does the device advance } \\
\text { smoothly? }\end{array}$ & $\begin{array}{l}\text { Is device securement easy } \\
\text { to obtain? }\end{array}$ \\
\hline $\begin{array}{l}\text { Product } \\
\text { information }\end{array}$ & $\begin{array}{l}\text { Is the information } \\
\text { contained in the package } \\
\text { clear and detailed? }\end{array}$ & \\
\hline
\end{tabular}

\subsection{Who Is Involved in a Product Evaluation?}

Evaluation is often performed on an 'ad hoc' basis without clear goals and objectives (Keselman et al. 2004). A team is created through the coordination of experts from various departments dependent on the device being evaluated. The process varies between hospitals and departments. Because the decision-making process for medical devices is very complex and subject to numerous constraints such as individual practitioner's choice, time and cost, the process of evaluation can be difficult at times. In addition to the functional aspects of devices, there exists another form of functionality referred to as 'soft functionality' (McDonagh et al. 2002). Soft functionality includes the emotional and other intangible, qualitative needs that affect the relationship of the user with the product. Soft functionality is a principal factor in the development of products and can have a bearing on the evaluation processes undertaken. Manufacturers are becoming keener to distinguishing their products from others and continue to explore innovative approaches to improve the symbolic dimensions of their products. One should be aware of their own emotions around products and how they 'feel' about them, as often the emotional needs of users are considered and exploited during the design of products (McDonagh et al. 2002). Group decision-making is imperative, and all stakeholders should have an input into product evaluation. This approach achieves goals that are beyond the range of one independent individual, as it is unlikely that one individual possesses the full skill set to allow a robust decision to be made. The evaluation team should be multidisciplinary and interdepartmental. Suggested members of this team include:

- End users.

- Infusion nurses.

- Nursing staff in areas that the products will be used.

- Medical staff.

- Infection control department.

- Pharmacy.

- Materials management.

- Purchasing/procurement department.

- Radiology physicians.

- Anaesthetic physicians.

- Biomedical department.

- Microbiology.

- Manufacturer.

Each of these committee members comes with a different agenda, be it costs, infection prevention or patients' safety. The purpose of this committee is to review all information gained from the preliminary evaluation using the evaluation tool. The committee acts as an end reviewer for product decisions, considers the qualities of each of the products and assesses the range available. Finally, the committee is responsible to either endorse or deny product selection, introduction or replacement.

\subsection{Working with Manufacturers During Evaluation}

The support of manufacturers during evaluations is invaluable. If any issues occur during evaluation of a product, the manufacturer should be responsive and offer help, advice and support. Many manufacturers now offer 'added-value' services. This means that rather than a focus only 
on product sales, clinical support by specialist clinicians is part of the service offered. This approach gives companies a competitive advantage (Trombetta 2010) as advice and support is delivered on site and helps to ensure correct use of products during the evaluation process. Many hospitals now see this added value as essential and recognize a level of dependence on them during evaluation processes.

\subsection{Right Evaluation Process}

Establish a clear timeframe during which an evaluation will take place; the length of time should be confirmed and agreed upon in advance. Decide as to where the evaluation will take place. Will this be in one department or clinical setting or across several settings? Introduce the evaluation tool to the evaluators, and explain the importance of detailed completion of the forms to all involved. Evaluation should provide feedback from all stakeholders and members of a team that will be using it. Additionally, ensure that individuals of the evaluation team have effective training regarding the use of the product to ensure correct use of the product or device and a more robust and meaningful evaluation. Ideally, the training is provided by the manufactures who are familiar with the products and take place as close to the evaluation commencement date as possible. Following the evaluation process, the results are collated, and findings are disseminated to the committee. Details of the chosen product should be communicated to all necessary individuals. Following introduction of the product, provide training to all practitioners who will be involved with its use. Thereafter, continuous evaluation of the product is imperative.

\subsection{Conclusion}

The number and range of products available within the field of vascular access continues to expand. New and innovative products that aim to reduce infections, prevent occlusions and improve patient safety are plentiful. To ensure the most suitable products are on our shelves, we must ascertain that the right evaluation of products is undertaken. The aim of product evaluation is multifaceted and includes identifying products and devices that meet specific performance outcomes, are safe for both patients and staff, ensure positive patient outcomes and are cost-effective for all stakeholders (Ventola 2008).

\section{Case Study}

Staff nurse Ricky Goldsworth attended a local Vascular Access Conference. One of the presentations involved a nurse practitioner discussing the introduction of a new vascular access device into her department. The presenter explained that, due to the design of the product, it was successfully dwelling for longer periods of time than traditional peripheral cannulas. She presented impressive audit results that demonstrated cost savings and, more importantly, an improved patient experience. This was the first time that Ricky had heard about such a device but was impressed with the results that had been presented. Ricky approached the presenter during the tea break and spoke a bit more about the devices. He found out that some of the companies that made the devices were exhibiting at the conference. He visited the appropriate stands and discussed the products with the company sales executives. He also picked up information on the product that he could take with him and read at his own convenience.

Once back at work, Ricky sat down with his manager and told her about the device. She asked him to write a proposal detailing how introducing the device might improve practice and patient care. She advised him to conduct an audit to determine what the situation was at present. This would give them a baseline to work from and evidence to show that change was required. She also 
gave him support to go and visit the nurse who had presented at the conference. This would give him a better insight into the product in practice.

Ricky wrote his proposal, provided published evidence and argued that introducing the devices could:

- Save money.

- Save time.

- Improve the patient experience.

- Potentially reduce infectious complications.

After the proposal was submitted, a multidisciplinary group was set up to commence an evaluation. An evaluation tool was developed to cover all required key points.

Devices from two companies that fit the criteria were included in the evaluation. A timeframe of 1 month was set for the evaluation. The evaluation took place in one ward area only. Full training was provided to key members of staff prior to the evaluation date.

Following the evaluation period, results were collated and discussed by the committee. The evaluation was successful and very positive. One product scored more highly than the others, and this device was selected as the most appropriate to purchase.

Subsequent training was rolled out ward by ward and department by department. Audit was continued and will continue to ensure the product remains effective and complication free.

\section{Summary of Key Points}

1. Clinical end users should be involved in the evaluation of infusion and vascular access-related technologies as they are the best qualified to evaluate the perfor- mance, safety, effectiveness and efficiency of products used in their clinical area or healthcare setting.

2. When possible, published evidence on performance of a product should be included in the product evaluation.

3. To ensure a successful product evaluation, before commencement, ensure there are clear goals and objectives set and that there is a multidisciplinary/ interdepartmental evaluation team in place.

4. Effective, well-informed product evaluation and purchasing can prove to ensure best patient outcomes.

\section{References}

Barton A, Ventura R, Vavrik B. Peripheral intravenous cannulation: protecting patients and nurses. $\mathrm{Br} \mathrm{J}$ Nurs. 2017;26(8):S28-33. https://doi.org/10.12968/ bjon.2017.26.8.S28.

Burns LR, Bradlow ET, Lee JA, Antonacci A. No title. Int J Technol Assess Healthc. 2007;23(4):445-63.

Cameron-Watson C. Port protectors in clinical practice: an audit. Br J Nurs. 2016;25(8):S25-31. https://doi. org/10.12968/bjon.2016.25.8.S25.

Jeanes A, Bitmead J. Reducing bloodstream infection with a chlorhexidine gel IV dressing. $\mathrm{Br} \mathrm{J}$ Nurs. 2015;24(19):S14-9. https://doi.org/10.12968/ bjon.2015.24.Sup19.S14.

Kelly LJ. Vascular access: viewing the vein. Br J Nurs. 2013;22(19 Suppl):S16-8. https://doi.org/10.12968/ bjon.2013.22.Sup19.S16.

Kelly LJ, Jones T, Kirkham S. Keeping the system closed. Br J Nurs. 2017;26(2):S14-9. IV Therapy Supplement.

Keselman A, Tang X, Patel VL, Johnson TR, Zhang J. Institutional decision-making for medical device purchasing: evaluating patient safety. Stud Health Technol Inform. 2004;107(Pt 2):1357-61. D040004983 [pii].

Lamperti M, Pittiruti M. II. Difficult peripheral veins: turn on the lights. Br J Anaesth. 2013;110(6):888-91. https://doi.org/10.1093/bja/aet078.

Lamperti M, Bodenham AR, Pittiruti M, Blaivas M, Augoustides JG, Elbarbary M, Pirotte T, Karakitsos D, Ledonne J, Doniger S, Scoppettuolo G, Feller-Kopman D, Schummer W, Biffi R, Desruennes E, Melniker LA, Verghese ST. International evidence-based recommendations on ultrasound-guided vascular access. Intens Care Med. 2012;38:1105-17. https://doi.org/10.1007/ s00134-012-2597-x. 
McDonagh D, Bruseberg A, Haslam C. Visual product evaluation: exploring users' emotional relationships with products. Appl Ergon. 2002;33(3):231-40. https://doi.org/10.1016/S0003-6870(02)00008-X.

Moureau NL, Flynn J. Disinfection of needleless connector hubs: clinical evidence systematic review. Nurs Res Pract. 2015;2015:796762. https://doi. org/10.1155/2015/796762.

Philips N. Berry \& Kohn's operating room technique. 12th ed. Ohio: Elsevier; 2017.

Phipps K, Modic A, O'Riordan MA, Walsh M. A randomized trial of the vein viewer versus standard technique for placement of peripherally inserted central catheters (PICCs) in neonates. J Perinatol. 2012;32:498-501. https://doi.org/10.1038/jp.2011.129.

Plkwer A. Does the position of the central venous catheter tip matter? Int J Intens Care. 2008;15(4):120-3. http:// www.embase.com/search/results?subaction=viewreco rd\&from=export\&id=L354396138

Robinson-Reilly M, Paliadelis P, Cruickshank M. Venous access: the patient experience. Support Care Cancer. 2016;24(3):1181-7. https://doi.org/10.1007/ s00520-015-2900-9.

Roldan CJ, Paniagua L. Central venous catheter intravascular malpositioning: causes, prevention, diagnosis, and correction. West J Emerg Med. 2015;16(5):65864. https://doi.org/10.5811/westjem.2015.7.26248.

Simon PO, Saad WE. Ultrasound-guided vascular access. Ultrasound Clin. 2012;7(3):283-97. https://doi. org/10.1016/j.cult.2012.04.001.

Trombetta B. Category captain management: an idea whose time has come in the pharmaceutical industry? Int J Pharmaceut Healthc Market. 2010;4(2):157-74. https://doi.org/10.1108/17506121011059768.

Ullman AJ, Kleidon T, Gibson V, Long DA, Williams T, McBride CA, Hallahan A, Mihala G, Cooke M, Rickard CM. Central venous access device SeCurement and Dressing Effectiveness (CASCADE) in paediatrics: protocol for pilot randomised controlled trials. BMJ Open. 2016;6(6):1-9. https://doi. org/10.1136/bmjopen-2016-011197.

Ventola CL. Challenges in evaluating and standardizing medical devices in health care facilities. P \& $\mathrm{T}$. 2008;33(6):348-59.

Ventura R, O'Loughlin C, Vavrik B. Clinical evaluation of a securement device used on midline catheters. Br J Nurs. 2016;25(14):S16-22. https://doi.org/10.12968/ bjon.2016.25.14.S16.

Open Access This chapter is licensed under the terms of the Creative Commons Attribution 4.0 International License (http://creativecommons.org/licenses/by/4.0/), which permits use, sharing, adaptation, distribution and reproduction in any medium or format, as long as you give appropriate credit to the original author(s) and the source, provide a link to the Creative Commons license and indicate if changes were made.

The images or other third party material in this chapter are included in the chapter's Creative Commons license, unless indicated otherwise in a credit line to the material. If material is not included in the chapter's Creative Commons license and your intended use is not permitted by statutory regulation or exceeds the permitted use, you will need to obtain permission directly from the copyright holder. 